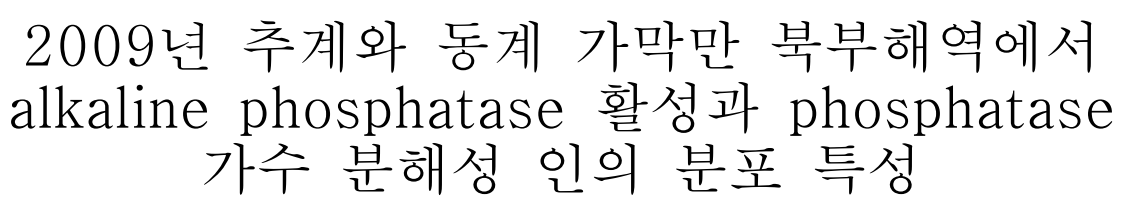

권형규·오석진 ${ }^{1 *} \cdot$ 양한섭

부경대학교 해양학과

${ }^{1}$ 부경대학교 해양과학공동연구소

\title{
Distribution Characteristics of Alkaline Phosphatase Activity and Phosphatase Hydrolyzable Phosphorus in Northem Gamak Bay in Autumn and Winter, 2009
}

\author{
Hyeong Kyu Kwon, Seok Jin $\mathrm{Oh}^{1 *}$ and Han-Soeb Yang \\ Department of Oceanography, Pukyong National University, \\ Busan 608-737, Korea \\ ${ }^{1}$ Korea Inter-University Institute of Ocean Science, Pukyong National University, \\ Busan 608-737, Korea
}

We investigated variations in alkaline phosphatase (APase) activity and alkaline phosphatase hydrolyzable phosphorus (APHP) in northern Gamak Bay from September to December 2009. Dissolved inorganic nitrogen (DIN) and dissolved inorganic phosphorus (DIP) decreased gradually, and the DIN/DIP ratio was higher than the Redfield ratio (16) based on molecular concentrations during most of the observation period. The total APase (T-APase) activity increased with decreasing DIP concentration; i.e., the Relationship between T-APase and DIP showed a high negative correlation $(\mathrm{r}=-0.80, P<0.001)$, with APase activity being a good indicator of DIP limiting the Redfield ratio. The T-APase was positively correlated with the concentration of chlorophyll $a(\mathrm{r}=0.73, P<0.001)$. This suggests that a major portion of APase activity in northen Gamak Bay seawater is attributed to phytoplankton. The proportion of APHP among dissolved organic phosphorus (DOP) was low in September and high in November. Thus, APase-producing phytoplankton may be able to grow by utilizing APHP as a phosphorus source in autumn when DIP is limiting. Thus, APase activity and the use of DOP by phytoplankton may play an important role in the growth of phytoplankton under DIP limiting conditions such as those of northern Gamak Bay.

Key words: Alkaline phosphatase (APase), Alkaline phosphatase hydrolyzable phosphorus (APHP), Dissolved inorganic phosphorus (DIP), Dissolved organic phosphorus (DOP), Northern Gamak Bay, Redfield ratio

\section{서 론}

부영양화가 진행된 우리나라의 연안 및 내만역은 여러 가지 환경문제가 발생하고 있으며, 그 중 식물플랑크톤의 이상 증 식은 많은 사회적인 문제로 대두되고 있다. 지금까지 현장에 서 식물플랑크톤 이상 증식을 제어하는 주요한 영양물질로 용존태 무기영양염만 생각되어 왔지만, 최근에 용존태 유기영 양염이 일부 식물플랑크톤의 이상 증식에 중요한 영양물질이 라는 것이 보고되고 있다 (Cembella et al., 1984; Oh et al., 2002). 특히 인에 대해서는 용존태 무기인 (dissolved inorganic phosphorous; DIP)으로 orthophosphate만을 고려해 왔지만, 최 근에 연안환경에서 $10 \mathrm{kda}$ 이상의 용존태 유기인 (dissolved organic phosphorous; DOP) 중 효소 활성에 의해 가수분해 되는 DOP도 중요한 인 공급원으로 알려져 있다 (Cembella et al., 1984; Suzumura et al., 1998). 이러한 DOP를 가수분해하

\footnotetext{
*Corresponding author: sjoh1972@pknu.ac.kr
}

는 효소를 phosphatase라고 하며, 해수 $\mathrm{pH}$ 와 유사한 환경에서 최적 활성을 보이는 효소가 alkaline phosphatase (APase)로, 그 활성은 종에 따라 크게 달라진다 (Cembella et al., 1984; Yamaguchi et al., 2004a; Yamaguchi et al., 2005; Oh et al., 2010). 해양에서 APase 활성에 대한 연구를 살펴보면 국외에 서는 일본의 Tokyo Bay (Taga and Kobori, 1978), Tokuyama Bay (Tanaka, 1984), Nagasaki Bay (Hirayama et al., 1989), Uranouchi Inlet (Yamaguchi et al., 2004b), Hiroshima Bay (Oh et al., 2005) 그리고 Red Sea (Li et al., 1998), Indian Ocean (Hope and Ullrich, 1999), Pacific Ocean (Koike and Nagata, 1997)등에서 활발히 진행되어 왔으며, 국내에서는 소양호 (Ahn et al., 1989; Choi and Kim, 2000)등 담수역에서 일부만 진행되었을뿐 해양에서의 연구는 전무한 실정이다.

한편, 해역에서 식물플랑크톤의 질소와 인의 제한 영양염 을 파악하는데 Redfield ratio (N/P)를 이용하여 16보다 높으면 인제한, 낮으면 질소가 제한된다고 알려져있다 (Redfield et 
al., 1963). 실제 마산만의 현장조사결과 DIN 농도가 $61.5 \mu \mathrm{M}$, $\mathrm{DIP}$ 농도가 $1.03 \mu \mathrm{M}$ 로 Redfield ratio가 59.7로 DIP가 제한요 인으로 작용하는 것처럼 보인다 (Lee et al., 1998). 하지만 이러한 DIP 농도는 성장 및 흡수 동력학실험 (growth and uptake kinetic experiment)으로부터 도출된 규조류 및 와편조 류의 반포화상수 (half saturation constant; Ks)보다 대부분 높아 $\mathrm{DIP}$ 가 식물플랑크톤의 제한 영양염이라고 말할 수 없다. APase 활성도는 DIP가 제한된 환경에서 $\mathrm{DOP}$ 를 가수분해하기 위해서 유도되며 (Berman, 1970; Reichardt, 1971; Pick, 1987; Chórst, 1991), 여러 연구에서 DIP가 제한된 연안역에서 APase 가 검출되기에 해역의 DIP 제한 정도를 파악하는데 많이 이용 되고 있다 (Gambin et al., 1999; Yamaughi et al., 2004b; Oh et al., 2005).

본 연구는 추계와 동계 가막만 북부해역에서 APase 활성과 그 활성에 의해 유도되는 가수 분해성 인을 측정함으로써 $\mathrm{DIP}$ 제한정도와 식물플랑크톤 성장에 있어 $\mathrm{DOP}$ 의 기여를 알아보기 위해 수행되었다.

\section{재료 및 방법}

가막만 북부해역의 해양환경 및 APase 활성의 변동특성을 파악하기 위해 2009년 9월부터 2009년 12월까지 총 4회에 걸쳐 수하식 홍합 양식장이 산재해 있고 약 $10 \mathrm{~m}$ 수심의 분지 지형을 가지는 정점 $1\left(34^{\circ} 43^{\prime} 54.9^{\prime \prime} \mathrm{N}, 127^{\circ} 40^{\prime} 19.3^{\prime \prime} \mathrm{E}\right)$ 과 양식 장의 영향을 받지 않고 약 $7 \mathrm{~m}$ 수심의 분지지형 밖에 위치하는 정점 $2\left(34^{\circ} 42^{\prime} 00.2^{\prime \prime} \mathrm{N}, 127^{\circ} 40^{\prime} 44.1^{\prime \prime} \mathrm{E}\right)$ 을 선정하여 현장관측을 실시하였다 (Fig. 1).

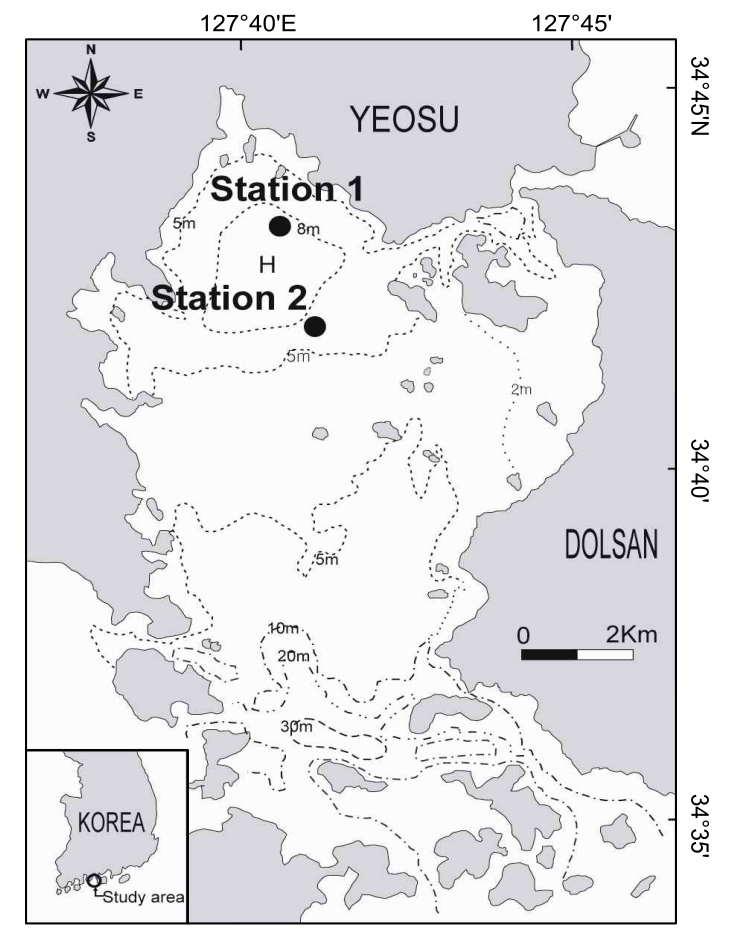

Fig. 1. Map showing the sampling stations in the northern Gamak Bay, Korea.
해양환경분석을 위한 시료채취는 반돈 채수기를 이용하여 표층 $(0 \mathrm{~m}), 2 \mathrm{~m}, 5 \mathrm{~m}$, 퇴적층 상부 $1 \mathrm{~m}$ 수층 $(\mathrm{B}-1 \mathrm{~m})$ 에서 채수하였다. 일반항목은 chlorophyll $a(\mathrm{Chl} . a)$, DIP, DOP 그리 고 용존태 무기질소 (dissolved inorganic nitrogen; DIN, $\mathrm{NH}_{4}-\mathrm{N}+\mathrm{NO}_{2}-\mathrm{N}+\mathrm{NO}_{3}-\mathrm{N}$ )로 해양환경공정시험법 (MOMAF, 2005)에 따라 측정하였다.

APase 활성의 측정은 해수시료 $25 \mathrm{~mL}$ 에 최종농도가 200 $\mu \mathrm{M}$ disodium phenylphosphate과 $0.6 \mathrm{M}$ tris (hydroxymethyl) amino methane $\mathrm{HCl}$ solution $\left(\mathrm{pH}\right.$ 9)을 첨가하여 $25^{\circ} \mathrm{C}$ 에서 24시 간 배양을 실시하였다. 배양 후 $2 \mathrm{mM}$ 의 aminoantipyrine 및 $5 \mathrm{mM}$ 의 ferricyanide를 첨가하여 시료를 발색시킨 후 disodium phenylphosphate의 가수분해로 축적된 phenol 농도를 $510 \mathrm{~nm}$ 에서 비색정량 하였다 (Yamaguchi et al., 2004a, 2004b). 입자태 APase (P-APase)와 용존태 APase (D-APase)의 분리를 위해서 공경이 $0.22 \mu \mathrm{m}$ 박막여과지 (Millipore GSWP)를 이용하여 여과한 후 그 여액을 D-APase로 간주하고, 총 APase (T-APase) 에서 D-APase를 공제한 농도를 P-APase로 가정하였다.

APase에 의해 가수분해 되는 DOP (alkaline phosphatase hydrolyzable phosphorus; APHP)를 측정하기 위해 시판용 APase 효소 (Sigma P7640, from bovine intestinal mucosa; 1 unit/ml)와 $1 \mathrm{M}$ 의 Tris 용액 ( $\mathrm{pH}$ 9)을 해수 $10 \mathrm{ml}$ 에 첨가하여 $37^{\circ} \mathrm{C}$ 에서 2 시간 배양을 실시하였다. 그리고 배양동안 박테리 아에 의한 분해 작용을 막기 위해 $5 \mathrm{mM}$ 의 sodium azide용액을 첨가하고, 배양 전과 후의 $\mathrm{DIP}$ 농도를 측정하여 증가한 $\mathrm{DIP}$ 농도를 APHP로 표현 하였다 (Oh et al., 2005).

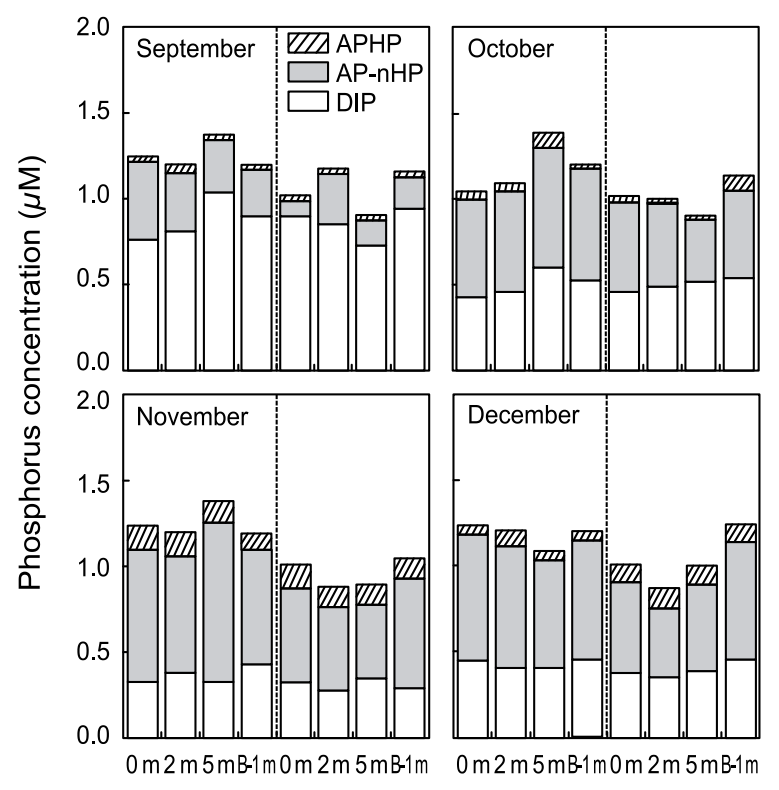

Station 1 Station $2 \quad$ Station $1 \quad$ Station 2

Fig. 2. Monthly variations of dissolved inorganic phosphorus (DIP), alkaline phosphatase hydrolyzable phosphorus (APHP) and alkaline phosphatase non-hydrolyzable phosphorus (AP-nHP) in the northern Gamak Bay, Korea. DOP is the sum of APHP and AP-nHP. 


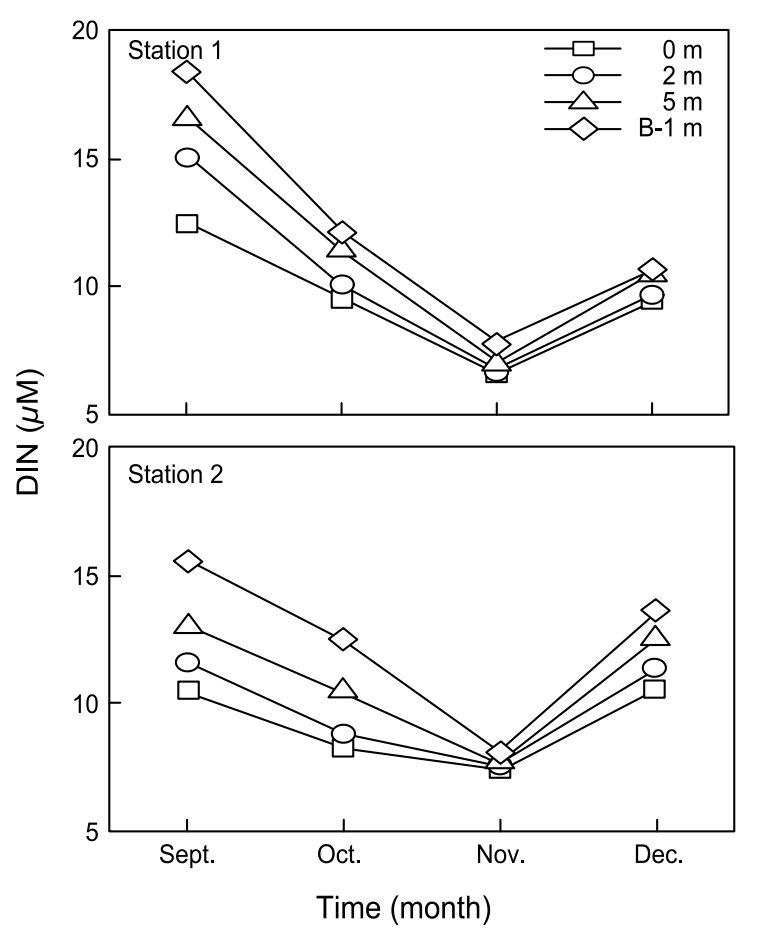

Fig. 3. Monthly variations of dissolved inorganic nitrogen (DIN) in the northern Gamak Bay, Korea.

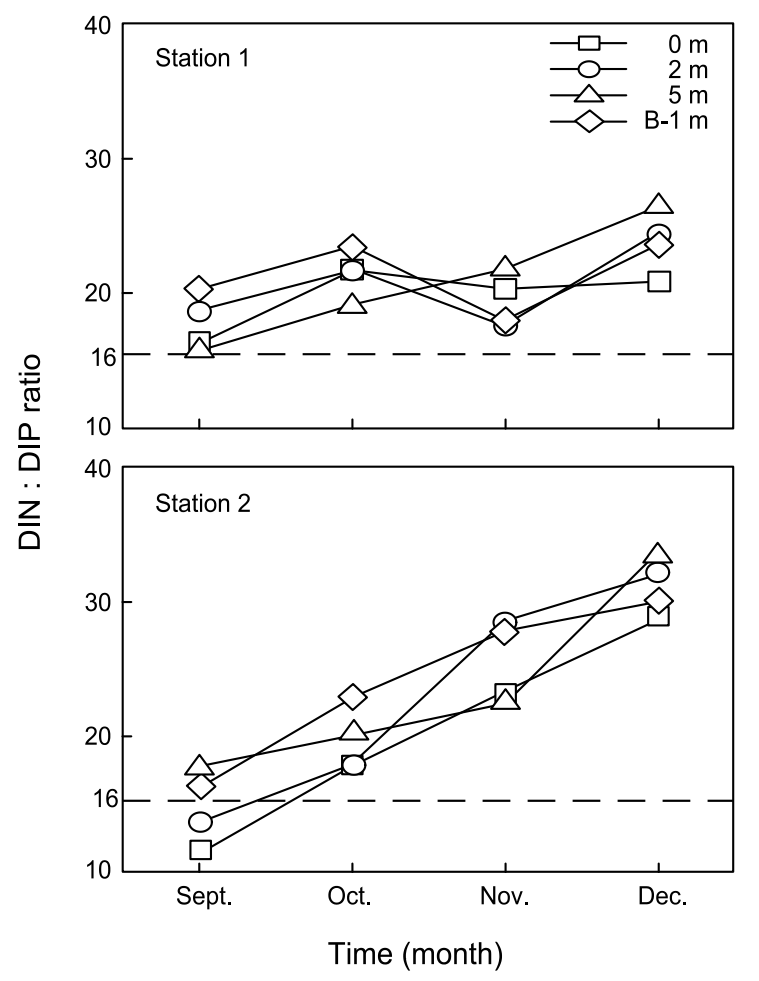

Fig. 4. Monthly variations of dissolved inorganic nitrogen (DIN) : dissolved inorganic phosphorus (DIP) in the northern Gamak Bay, Korea. Dot lines indicates Redfield ratio (16) of N/P based on molecular concentrations.

\section{결과 및 고찰}

해양환경 특성

$\mathrm{DIP}$ 는 정점 1 에서 $0.32 \sim 1.04 \mu \mathrm{M}$ (평균 \pm 표준편차; $0.54 \pm$ $0.22 \mu \mathrm{M})$ 이며, 정점 2 는 $0.27 \sim 0.95 \mu \mathrm{M}(0.35 \pm 0.22 \mu \mathrm{M})$ 의 변동 범위를 나타내었다. 정점 1이 정점 2보다 다소 높은 농도 를 보였으며, 2009년 9월부터 12월까지 점차 감소하는 경향이 었다(Fig. 2). DOP는 정점 1 에서 $0.29 \sim 1.06 \mu \mathrm{M}(0.67 \pm 0.21$ $\mu \mathrm{M})$ 이며, 정점 2에서 $0.11 \sim 0.76 \mu \mathrm{M}(0.49 \pm 0.20 \mu \mathrm{M})$ 범위였으 며, $\mathrm{DIP}$ 와 유사하게 정점 1 이 정점 2 보다 다소 높은 농도를 나타내었다 (Fig. 2). 용존태 총인 (dissolved total phosphorus; $\mathrm{DTP}$ )중 $\mathrm{DOP}$ 가 차지하는 비율은 9월에 정점 1과 2에서 각각 평균 $30 \%$ 와 $18 \%$ 로 비교적 낮은 비율을 보였지만, 그 외의 시기에는 $50 \%$ 이상이었다. DIN은 정점 1 에서 $6.56 \sim 18.39 \mu \mathrm{M}$ $(10.86 \pm 3.45 \mu \mathrm{M})$, 정점 2에서 7.44 15.52 $\mu \mathrm{M}(10.58 \pm 2.47 \mu \mathrm{M})$ 의 변동범위를 보였다 (Fig. 3). 정점 1과 정점 2에서 뚜렷한 차이는 보이지 않았으며, 변동양상은 DIP와 유사하였다. DIN 과 $\mathrm{DIP}$ 의 비는 정점 1 에서 $15.86 ~ 26.43(20.70 \pm 2.96)$ 이며, 정점 2는 11.63 $33.43(22.82 \pm 6.72)$ 의 변동범위를 나타냈으며, 9월 에서 12 월까지 점차 증가하는 경향으로, 대부분의 시기에 Redfield 비(16) 보다 높았다 (Fig. 4).

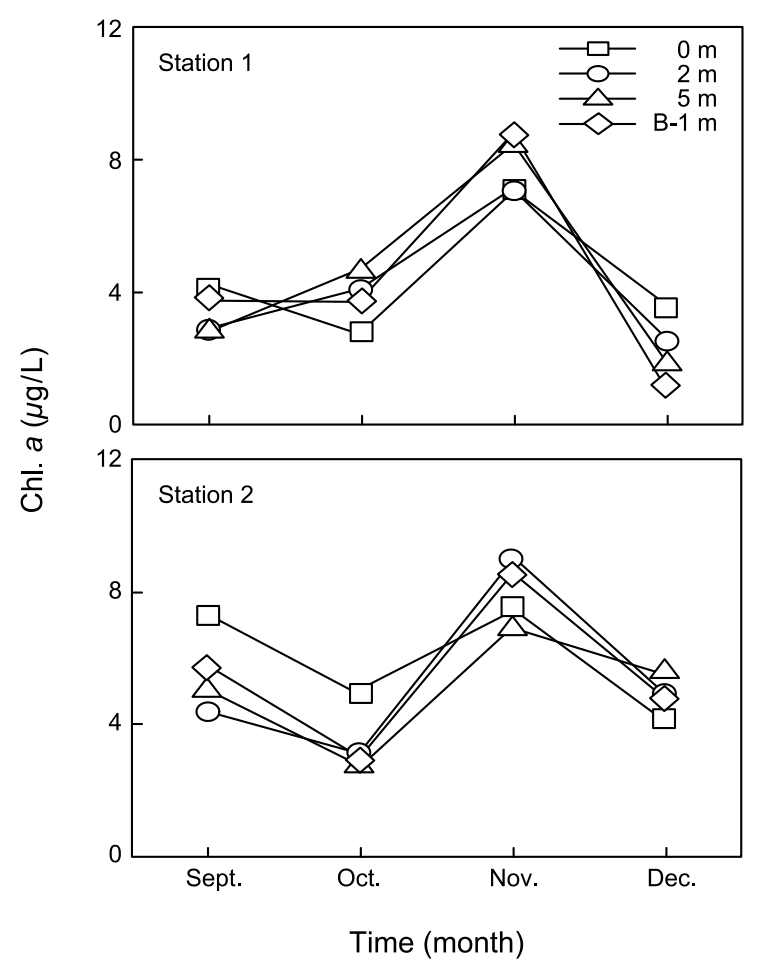

Fig. 5. Monthly variations of chlorophyll $a$ (Chl. $a$ ) in the northern Gamak Bay, Korea.

Chl. $a$ 는 정점 1 에서 $1.20 \sim 8.71 \mu \mathrm{g} / \mathrm{L}(4.33 \pm 2.27 \mu \mathrm{g} / \mathrm{L})$, 정점 2에서 $2.79 ~ 8.97 \mu \mathrm{g} / \mathrm{L}(5.46 \pm 1.91 \mu \mathrm{g} / \mathrm{L})$ 의 범위를 보였다. 정 점 1과 정점 2에서 2009년 9월부터 10월에 이르는 기간 동안 
점차 감소하였으며, 11 월에 정점 1 과 2에서 평균 $7.81 \mu \mathrm{g} / \mathrm{L}$ 과 $7.91 \mu \mathrm{g} / \mathrm{L}$ 로 가장 높은 생물량은 보였으며, 이후 다소 감소하 였다 (Fig. 5). 전체적으로 정점 1이 정점 2에 비해서 다소 낮은 Chl. $a$ 농도를 보였는데, 이는 정점 1 에 위치한 양식장에 서 양식생물의 섭이활동이 중요한 원인으로 생각된다.

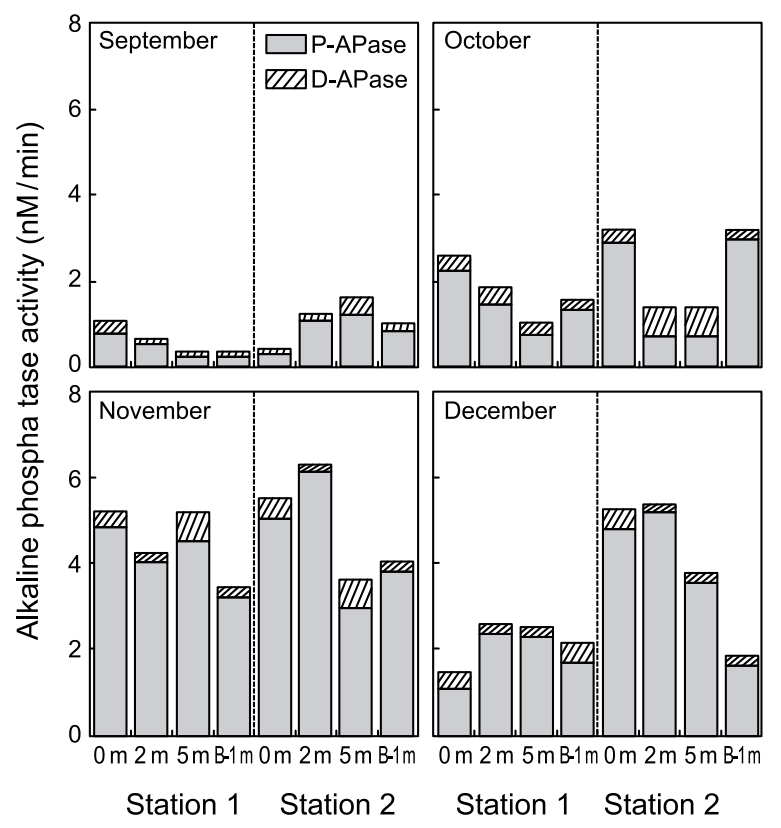

Fig. 6. Monthly variations of particulate alkaline phosphatase (P-APase) activity and dissolved alkaline phosphatase (D-APase) in the northern Gamak Bay, Korea. Total alkaline phosphatase (T-APase) activity is the sum of P-APase activity and D-APase activity.

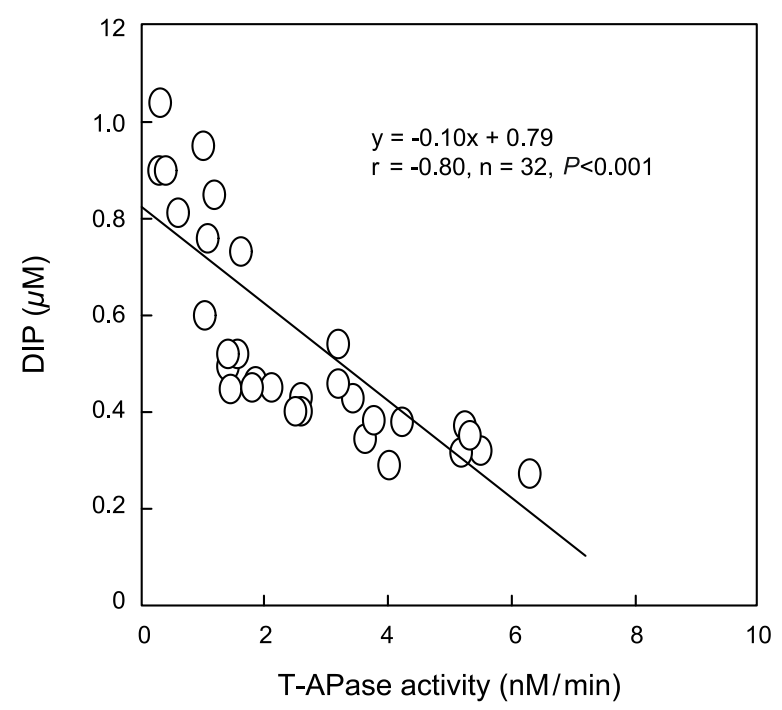

Fig. 7. Relationship between total alkaline phosphatase (T-APase) activity and dissolved inorganic phosphorus (DIP).
Alkaline phosphatase 활성의 변동특성

$\mathrm{T}$-APase 활성은 정점 1 에서 $0.32 \sim 5.21 \mathrm{nM} / \mathrm{min}(2.26 \pm 1.58$ $\mathrm{nM} / \mathrm{min})$, 정점 2에서 $0.40 \sim 6.30 \mathrm{nM} / \min (3.07 \pm 1.86 \mathrm{nM} / \mathrm{min})$ 범 위로, DIP의 제한에 따라 전 시기에서 활성이 유도되었다. 활성의 시공간적인 변화는 $\mathrm{DIP}$ 와 역으로 정점 2에서 정점 1 보다 다소 높은 활성을 보였으며, $\mathrm{DIP}$ 농도 감소와 함께 증가 하는 경향이 나타났다 (Fig. 6). 실제 T-APase와 DIP의 상관관 계를 검토한 결과 높은 음의 상관관계를 나타내어 $(\mathrm{r}=-0.80$, $P<0.001$; Fig. 7), DIP농도가 APase 활성을 조절하는 중요한 요인으로 나타났다. 또한 APase의 기원을 밝히기 위해 T-APase 활성과 Chl. $a$ 의 상관관계를 구한 결과 높은 상관관계 를 보여 박테리아보다는 식물플랑크톤으로부터 유도되었음 을 알 수 있다 (Fig. 8). 이는 일본 Hiroshima 만 그리고 Pomeranian Bight에서 APase 와 Chl. $a$ 의 높은 양의 상관관계 로부터 APase는 식물플랑크톤으로부터 유도되었다는 보고와 일치하였다 (Nausch, 1998; Oh et al., 2005). 따라서 추.동계 가막만 북부해역의 경우 높은 Redfield 비 (DIN:DIP)와 APase 활성에 따라 DIP가 식물플랑크톤의 성장에 중요한 제한 요소 임을 알 수 있다.

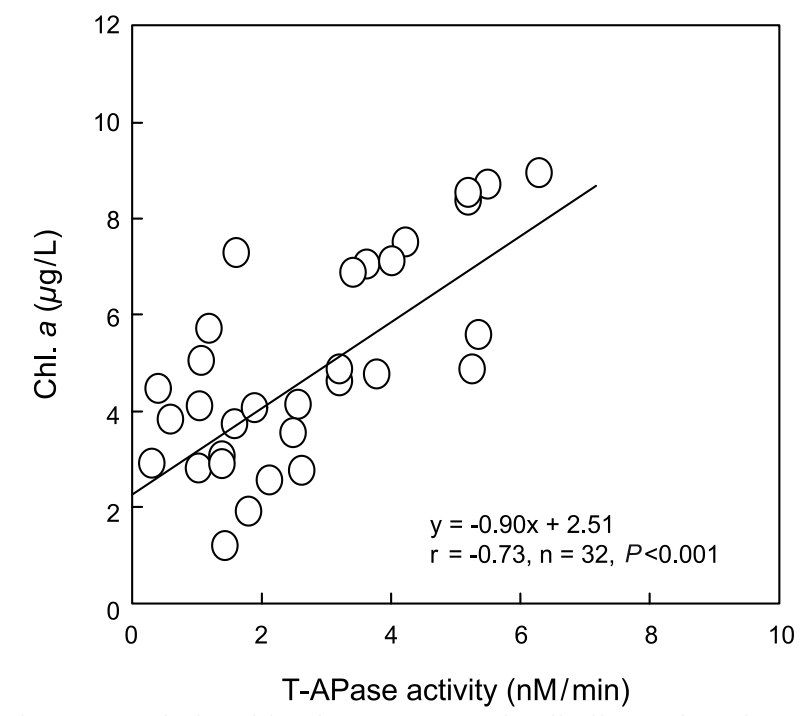

Fig. 8. Relationship between total alkaline phosphatase (T-APase) activity and chlorophyll $a$ (Chl. $a$ ).

본 연구에서 유도된 T-APase는 사용된 기질과 분석방법이 다르기 때문에 타 해역과 직접적인 비교는 힘들지만, 가막만 북부해역의 APase 활성은 동일한 기질 (phenylphosphate)과 방법으로 측정된 일본의 Uranouchi Inlet (1.2-70.1 nM/min; Yamaguchi et al., 2004b)과 Tokuyama 만 (0-141.6 nM/min; Tanaka, 1984)보다는 낮은 활성을 보였다. 일본의 두 해역의 경우, 1979년부터 발효된 Seto 내해 환경 보전 특별 조치법 (Law Concerning Special Measures for Conservation of the Environment of the Seto Inland Sea) 발효로 인 정화기준 강화 및 인이 함유된 세제 제조 금지에 따라 해양으로 인 유입이 감소되어 춘·하계의 경우 DIP 농도가 검출한계 이하의 값을 보이는 등 (Yamamoto 
et al., 2002), 가막만 북부해역보다 DIP가 크게 제한되어 있기 때문에 높은 활성이 보인 것으로 생각된다.

T-APase 중 D-APase 활성은 정점 1에서 $0.06 \sim 0.67 \mathrm{nM} / \mathrm{min}$ $(0.28 \pm 0.16 \mathrm{nM} / \mathrm{min})$, 정점 2에서 $0.09 \sim 0.67 \mathrm{nM} / \mathrm{min}(0.33 \pm 0.20$ $\mathrm{nM} / \mathrm{min}$ )로 9월이 가장 낮은 활성을 보였다 (Fig. 6). T-APase 중 D-APase의 비율은 9월에 평균 $8 \%$ 로 가장 낮은 비율이었으 며, 10 월부터 12 월까지 $15 \%$ 로 유사한 비율을 보였다. 일반적 으로 식물플랑크톤과 박테리아는 자연군집에서 D-APase를 생성하는 주요한 유기물로 알려져 있다 (Nausch, 1998). APase 는 세포벽에 느슨하게 결합되어 있기 때문에 세포 용해나 상위포식자의 섭식작용과 같은 외부의 물리적 작용에 의해서 쉽게 주변해수로 분리되게 된다. 하지만 D-APase는 P-APase 보다 상대적으로 안정하기 때문에 수중에서 수일동안 존재하 면서 활성을 보이며 (Li et al., 1998; Nausch, 1998), DIP의 결핍이 나타나면 수괴 중에서 2 12시간 이내에 최대 활성이 나타난다 (Block and Grossman, 1988). 따라서 가막만 북부해 역에서 박테리아의 분해와 이류확산과 같은 물리적인 과정에 따라 DIP가 공급될 수도 있지만, 식물플랑크톤에서 유리된 $\mathrm{D}$-APase도 $\mathrm{DOP}$ 의 재무기화에 기여할 것으로 생각된다.

Table 1. A theoretical concept for dissolved inorganic phosphorus (DIP) availability and alkaline phosphatase (APase) activity of phytoplankton communities suggested by Li et al. (1998)

\begin{tabular}{ccc}
\hline $\begin{array}{c}\text { Dissolved } \\
\text { APase } \\
\text { activity }\end{array}$ & $\begin{array}{c}\text { Particulate } \\
\text { APase } \\
\text { activity }\end{array}$ & DIP limitation \\
\hline Absent & Low and absent & No DIP limitation \\
Low & High & Recent DIP limitation (hour to day) \\
High & High & Persisting DIP limitation (day to week) \\
High & Low of absent & Recent relief from DIP limitation \\
\hline
\end{tabular}

해수 중에 유리된 D-APase와 식물플랑크톤에 표면에 위치 한 P-APase를 측정함에 따라 현장해수 중의 DIP의 제한 정도 를 경시간적으로 파악할 수 있다 (Li et al., 1998; Table 1). 해수 중에 D-APase와 식물플랑크톤의 P-APase가 낮거나 검출 되지 않는다면 해역에서 DIP 제한이 계속해서 없는 상태이며, D-APase가 낮고 P-APase가 높으면 최근에 DIP가 제한된 해역 이고, 높은 D-APase와 P-APase의 경우 장기간 DIP 제한이 있는 해역으로 판단할 수 있다. 마지막으로 높은 D-APase와 낮은 P-APase의 경우 최근에 DIP 제한이 없어진 것을 암시한 다. 본 해역의 경우 9월에 다른 계절보다 낮은 D-APase와 $\mathrm{P}-\mathrm{APase}$ 로 $\mathrm{DIP}$ 의 제한이 없는 것으로 보이지만, 11 월에 낮은 $\mathrm{D}-\mathrm{APase}$ 와 높은 P-APase로 최근에 DIP 제한된 해역임을 알 수 있다 따라서, 11월만 D-APase 및 T-APase를 측정하더라도 DIP 제한의 시간적인 변화양상을 파악할 수 있다. 이러한 효소 활성에 따른 영양제한 정도는 단순히 영양염의 절대 농도 및 Redfield 비보다 영양염을 직접 이용하는 식물플랑크톤 생리적인 측면을 고려하였기 때문에 정확한 영양염 제한 정도
를 판단할 수 있는 유용한 지표로 생각된다.

생물학적으로 이용 가능한 $\mathrm{DOP}$ 의 중요성

$\mathrm{APHP}$ 는 정점 1 에서 $0.02 \sim 0.14 \mu \mathrm{M}(0.06 \pm 0.04 \mu \mathrm{M})$ 이며, 정점 2에서 $0.02 \sim 0.14 \mu \mathrm{M}(0.07 \pm 0.05 \mu \mathrm{M})$ 범위를 보였다. 전 체 $\mathrm{DOP}$ 중 $\mathrm{APHP}$ 가 차지하는 비율은 9월에 7\%로 가장 낮은 비율이었으며, 11 월에 $17 \%$ 로 가장 높은 $\mathrm{APHP}$ 의 비율을 보였 다 (Fig. 2). 이는 9월에 식물플랑크톤 성장으로 분해성 DOP가 소비되었거나, 강수 등에 따라 육원성 물질의 유입으로 난분 해성 $\mathrm{DOP}$ 이 증가되었기 때문으로 생각된다. 그리고 11월은 $\mathrm{DIP}$ 제한에 따라 APHP는 APase 합성능력을 보이는 식물플랑 크톤의 DIP 공급원으로써 중요한 역할을 담당하였을 것으로 판단된다.

$\mathrm{DOP}$ 중 $10 \mathrm{kDa}$ 이하의 분자량을 가지는 저분자량의 $\mathrm{DOP}$ 는 외양에서 생물반응성이 높은 것으로 알려져 있으나, 연안역의 경우 육원성 기원이 많기 때문에 생물에 대한 반응이 반대로 낮게 나타난다 (Suzumura et al., 1998). 고분자량의 경우 ester 결합수에 따라 phosphomonoester (PME)와 phosphodiester (PDE)로 나뉘고, 난분해성 DOP인 phosphonate가 일정부분을 차지하고 있다. phosphonate는 화학적으로 안정하여 가수분해 효소에 의해서 가수분해 되지 않으며 태평양의 표층수의 경우 $\mathrm{DOP}$ 의 약 $25 \%$ 의 비율로 존재한다 (Clark et al., 1998). 그리고 $\mathrm{PME}$ 와 $\mathrm{PDE}$ 는 각각 APase와 phosphodiesterase에 의해서 식물 플랑크톤이 이용할 수 있는 DIP로 가수분해 되며, Tokyo만에 서 $\mathrm{DOP}$ 중 $\mathrm{PME}$ 와 $\mathrm{PDE}$ 의 비율이 약 $1: 3$ 의 비율로 존재한다고 보고되어 있다 (Suzumura et al., 1998). 본 연구에서는 시판용 $\mathrm{APase}$ 에 의해 가수분해 되는 $\mathrm{DOP}$ 즉, $\mathrm{PME}$ 의 농도만 고려되 었기에 실제 식물플랑크톤이 이용 가능한 $\mathrm{PDE}$ 와 같은 $\mathrm{DOP}$ 의 농도가 반영되지 않았기 때문에 실제 식물플랑크톤이 이용 가능한 가수 분해성 인의 농도는 현재 농도에서 약 3 배 정도 높을 가능성이 있다.

일반적으로 반포화상수 $(\mathrm{Ks})$ 는 제한영양염에 대한 친화성 (affinity)을 나타내는 기준으로 (Dugdale, 1967), 이 값이 높을 수록 영양염에 대한 친화성이 낮으며, 세포크기가 큰 종이 대략 높은 Ks 값을 보인다 (Eppley et al., 1969). 가막만에서 연중 출현하는 주요 우점종인 Skeletonema costatum 의 경우 영양염 흡수 동력학 실험에 따라 도출된 $\mathrm{Ks}$ 가 0.48-0.68 $\mu \mathrm{M}$ 로 비교적 낮은 $\mathrm{Ks}$ 로 측정되었다 (Li et al., 1999; Tarutani and Yamamoto, 1994). 추·동계 가막만 북부해역의 DIP의 농도는 이보다 더 낮은 농도를 보였는데, 이들 식물플랑크톤이 본 해역에서 우점화하기 위해서는 DIP를 제외한 다른 인원이 필요할 것이다. Oh et al. (2010)과 Yamaguchi et al. (2004a)에 따르면 S. costatum은 DOP를 이용하기 위해 APase를 활성화하 며, 실제 여러 가지 PME를 첨가한 batch 배양실험에서도 DIP 첨가한 배양구와 유사하게 성장하였다. 따라서 가막만 북부해 역에서 우점하고 있는 식물플랑크톤은 APase를 활성화시킬 수 있는 종인 것을 간접적으로 알 수 있으며, APase의 활성은 $\mathrm{DIP}$ 제한 환경에서도 우점화 전략에 큰 역할을 할 것으로 기대된다. 


\section{사 사 \\ 본 논문은 부경대학교 해양과학공동연구소의 지원에 따라 수행된 연구로 지원기관에 감사를 표합니다.}

\section{참고문헌}

Ahn TS, Kim BC and Cho KS. 1989. On the kinetics of alkaline phosphatase activity in Lake Soyang. Kor J Limnol 22, 219-225.

Berman T. 1970. Alkaline phosphatase and phosphorus availability in Lake Kinneret. Limnol Oceanogr 15, 663-674.

Block MA and Grossman AR. 1988. Identification and purification of a repressible alkaline phosphatase from Anacystis nidulans R2. Plant Physiol 84, 1179-1184.

Cembella AD, Antia NJ and Harrison PJ. 1984. The utilization of inorganic and organic phosphorus compounds as nutrients by eukaryotic microalgae: a multidisciplinary perspective: Part 1 . CRC Critic. Rev. Microbiol 10, 317-391.

Choi KS and Kim BC. 2000. A study on the kinetics parameters of alkaline phosphatase by algae. Kor $\mathrm{J}$ Limnol 33, 380-386.

Chróst RJ. 1991. Environmental control of the synthesis and activity of aquatic microbial ectoenzymes. In: Microbial Enzymes in Aquatics Environments. Chróst RJ, ed. Springer-Verlag, New-York, U.S.A. 29-59.

Clark LL, Ingall ED and Bernner R. 1998. Marine phosphorus is selectively remineralized. Nature, 426.

Dugdale RC. 1967. Nutrient limitation in the sea: dynamic, identification and significance. Limnol Oceanogr 12, 685-695.

Eppley RW, Rogers JN and McCarthy JJ. 1969. Half-saturation constants for uptake of nitrate and ammonium by marine phytoplankton. Limnol Oceanogr 14, 912-920.

Gambin F, Boge G and Jamet D. 1999. Alkaline phosphatase in a littoral Mediterranean marine ecosystem: role of the main plankton size classes. Mar Environ Res 47, 441-456.

Hirayama K, Doma T, Hamamura N and Muramatsu T. 1989. Role of alkaline phosphatase activity in the growth of red tide organism. In: Red Tides: Biology, Environmental Science and Toxicology. Okaichi T, Anderson DM and Nemoto T, eds. Elsevier, New York, U.S.A. 317-320.
Hope HG and Ullrich S. 1999. Profiles of ectoenzymes in the Indian Ocean: phenomena of phosphatase activity in the mesopelagic zone. Aquat Microbiol Ecol 19, 139-148.

Koike I and Nakata T. 1997. High potential activity of exracellular alkaline phosphatase in deep water of the central Pacific. Deep-Sea Res $\Pi$ 44, 2283-2294.

Lee CH, Kwon YT, Yang KS, Jang PG and Han SD. 1998. Loading characteristics and environmental changes in closed coastal water. J Kor Soc Mar Environ Eng 1, 60-70.

Li H, Veldhuis MJW and Post AF. 1998. Alkaline phosphatase activities among planktonic communities in the northern Red Sea. Mar Ecol Prog Ser 173, 107-115.

Li T, Shi Z, Qiu C and Wang Q. 1999. A study on the uptake rate of the nutrients by Skeletonema costatum and Nitzschia closterium and the environmental effects. Oceanologia et Limnologia Sinica 30, 640-645.

MOMAF (Ministry of Maritime Affaris \& Fisheries). 2005. Standard methods for the examination of sea water, sediment and marine organism. Seoul, Korea. 389.

Nausch M. 1998. Alkaline phosphatase activities and the relationship to inorganic phosphate in the Pomeranian Bight (southern Baltic Sea). Aquat Microb Eco 16, 87-94.

Oh SJ, Yamamoto T, Kataoka Y, Matsuda O, Matsuyama Y and Kotani Y. 2002. Utilization of dissolved organic phosphorus by the two toxic dinoflagellates, Alexandrium tamarense and Gymnodinium catenatum (Dinophyceae). Fish Sci 68, 416-424.

Oh SJ, Yoon YH, Yamamoto T and Matsuyama Y. 2005. Alkaline phosphatase activity and phosphatase hydrolyzable phosphorus for phytoplankton in Hiroshima Bay, Japan. Ocean Science Journal 40, 183-190.

Oh SJ, Kwon HK and Yang HS. 2010. Alkaline phosphatase activity and utilization of dissolved organic phosphorus by phytoplankton isolated from Korean coastal waters. J Kor Soc Oceanogr 15, 16-24.

Pick FR. 1987. Interpretations of alkaline phosphatase activity in Lake Ontario. Can J Fish Aquat Sci 44, 2087-2094.

Redfield AC, Ketchum BH, Richard FA. 1963. The influence of organisms in the composition of seater. In: The sea. Hill MN, ed. Interscience, New York, 
U.S.A. 26-77.

Reichardt W. 1971. Catalytic mobilization of phosphate in lake water and by Cyanophyta. Hydrobiol 38, 377-394.

Suzumura M, Ishikawa K and Ogawa H. 1998. Characterization of dissolved organic phosphorus in coastal seawater using ultrafiltration and phosphohydrolytic enzymes. Limnol oeanogr 43, 1553-1564.

Taga N and Kobori H. 1978. Phosphatase activity in eutrophic Tokyo Bay. Mar Biol 49, 223-229.

Tanaka K. 1984. Measurement method of alkaline phosphatase activity in seawater. Annual report of Yamaguchi Prefectural Environmental Pollution Research Center 9, 134-139.

Tarutani K and Yamamoto, T. 1994. Phosphate uptake and growth kinetics of Skeletonema costatum isolated from Hiroshima Bay. J Fac Appl Biol Sci 33, 59-64. Yamaguchi H, Nishijima T, Nishitani H, Fukami K and Adachi M. 2004a. Organic phosphorus utilization and alkaline phosphatase production of 3 red tide phytoplankton. Nippon Suisan Gakkaishi 70, 123130.
Yamaguchi H, Nishijima T, Oda A, Fukami K and Adachi M. 2004b. Distribution and variation of alkaline phosphatase activity and phsphatase hydrolyzable phosphorus in coastal seawater. Nippon Suisan Gakkaishi 70, 333-342.

Yamaguchi H, Sakou H, Fukami K, Adachi M, Yamaguchi $M$ and Nishijima N, 2005. Utilization of organic phosphorus and production of alkaline phosphatase by the phytoplankton, Heterocapsa circularisquama, Fibrocapsa japonica and Chaetoceros ceratosporum. Plankton Biol Ecol 52, 65-75.

Yamamoto T, Hashimoto T, Tsuji K, Matuda $\mathrm{O}$ and Tarutani K. 2002. Spatial and temporal variations of biophilic elements in Hiroshima Bay, Japan, during 1991-2000, with special reference to the deviation of phytoplanktonic $\mathrm{C}: \mathrm{N}: \mathrm{P}$ ratio from the Redfield ratio. Bull Coast Oceanogr 39, 163-169.

2010년 7월 12일 접수

2010년 9월 7일 수정

2010년 10월 11일 수리 